\title{
NOVEL CUCURBITACIN HYBRID ANALOGS EXHIBIT CYTOTOXIC EFFECTS AGAINST TRIPLE NEGATIVE BREAST CANCERS (TNBC) \\ Felix Acheampong ${ }^{1}$, Fathi Halaweish1
}

'Department of Chemistry and Biochemistry, South Dakota State University, Brookings, SD 57007, USA.

\section{Background}

Triple negative breast cancer (TNBC) accounts for about $20 \%$ of all breast cancer cases and has the worst prognosis ${ }^{1}$. It does not respond to hormone therapy due to under expression of estrogen receptor (ER), progesterone receptor, and human epidermal growth factor receptor 2 (HER2). Despite intensive drug discovery efforts, no targeted small-molecule medicine is approved by the U.S. Food and Drug Administration (FDA) for treating TNBC. In this study, we demonstrated that estrone hybrid analogs (with modified cucurbitacin pharmacophores) uniquely inhibit the proliferation of TNBC via suppression of epidermal growth factor receptor (EGFR) signaling.

\section{Study Approach}

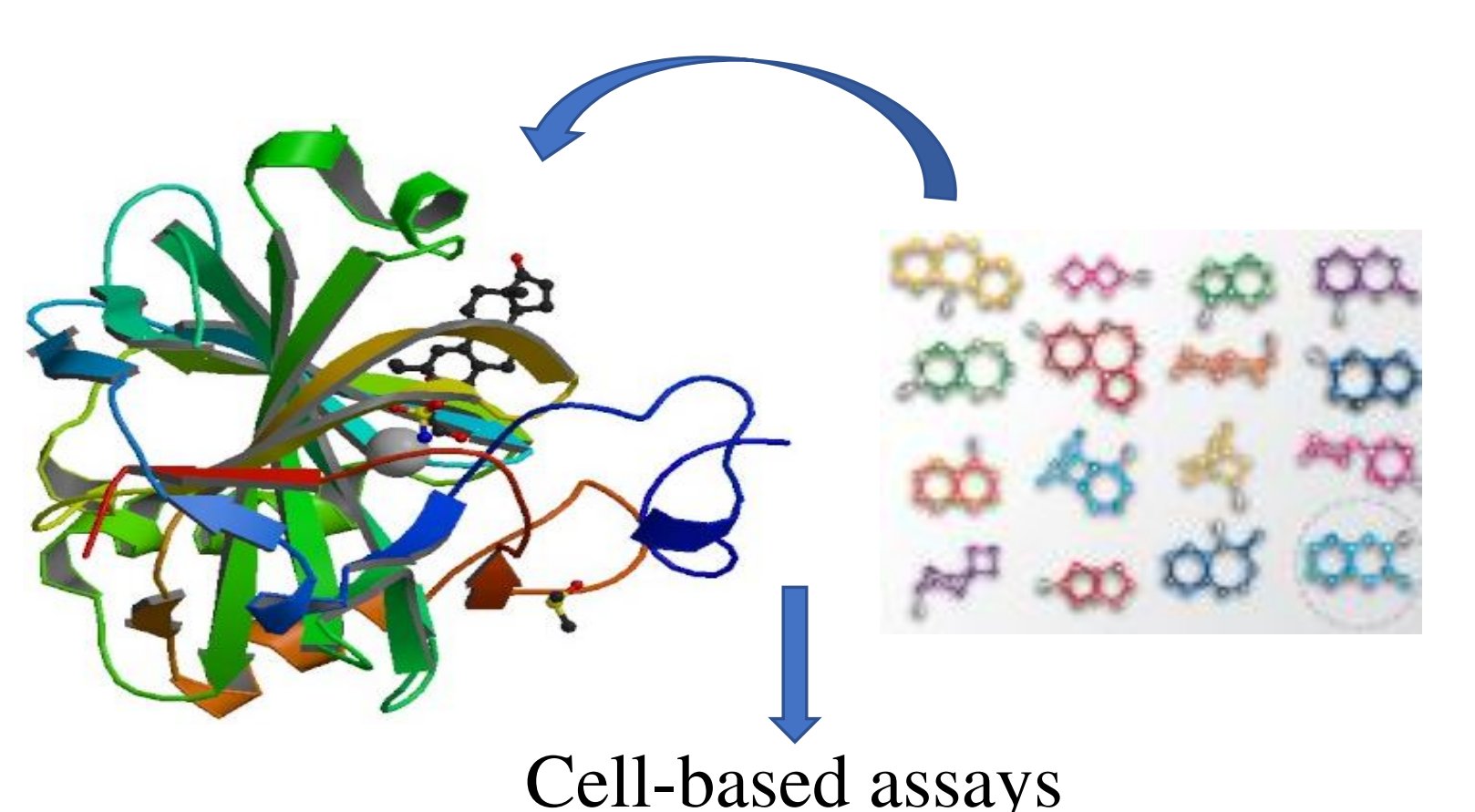

Cell-based assays

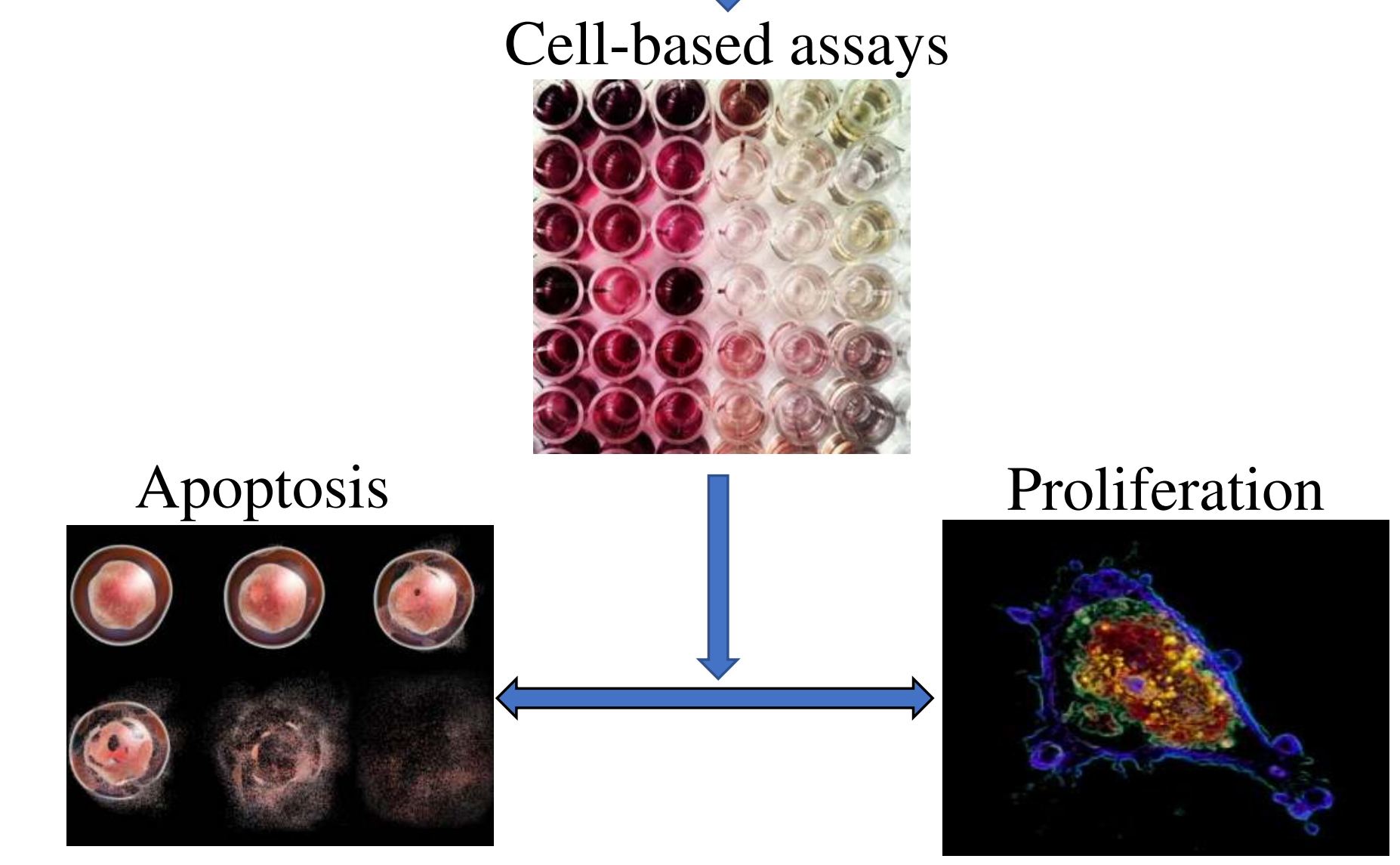

Figure 1. Design, synthesis and biological evaluation Compounds were designed in silico against EGFR and promising hits synthesized. Hits were evaluated in cellbased assays.

\section{Study Findings}

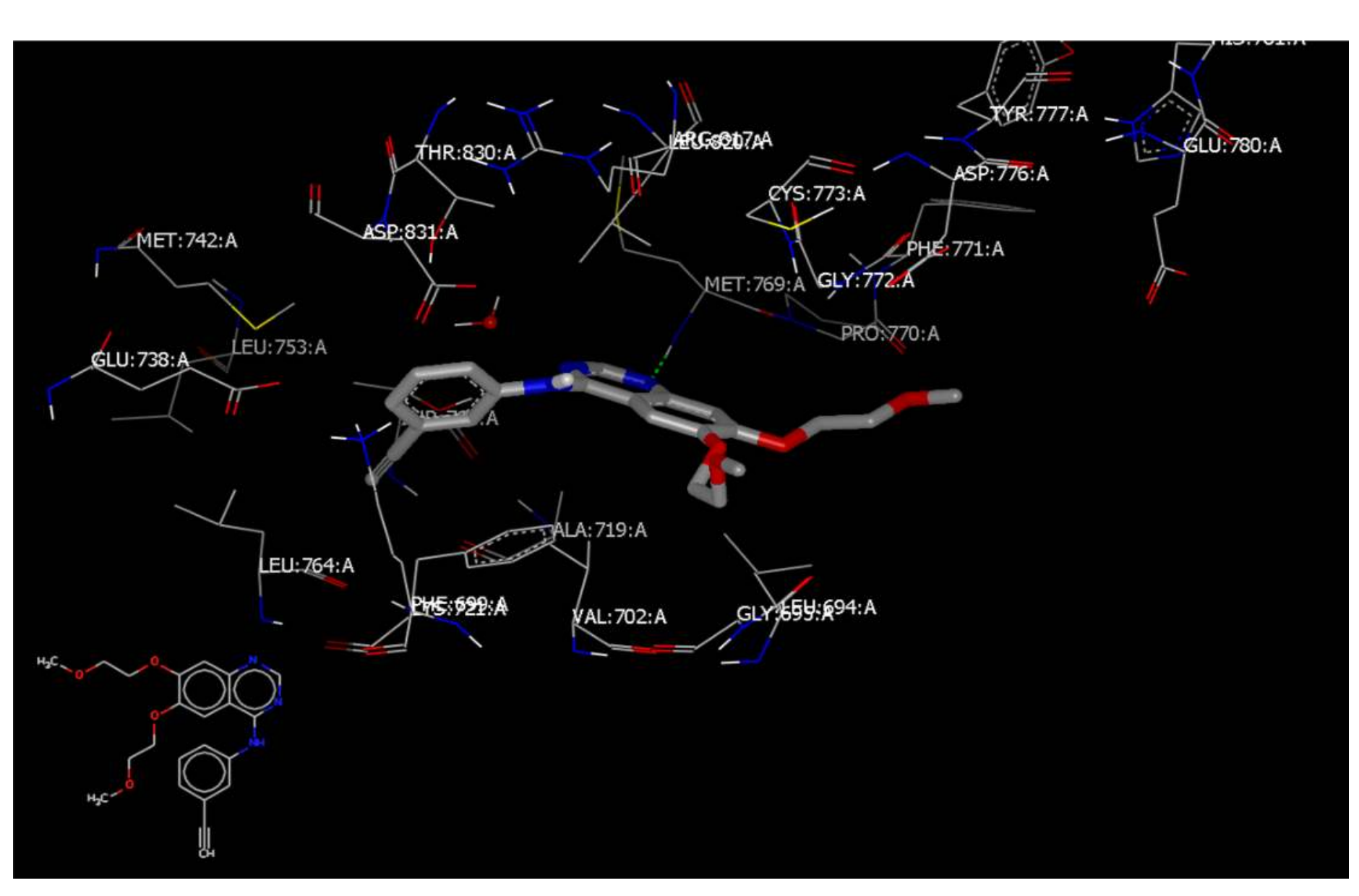

Figure 2. 3D visual representation of reference drug, erlotinib, docked against EGFR binding site. There is hydrogen bonding from the pyrimidine-N2 of erlotinib towards MET769A of $1 \mathrm{M} 17$ binding site.

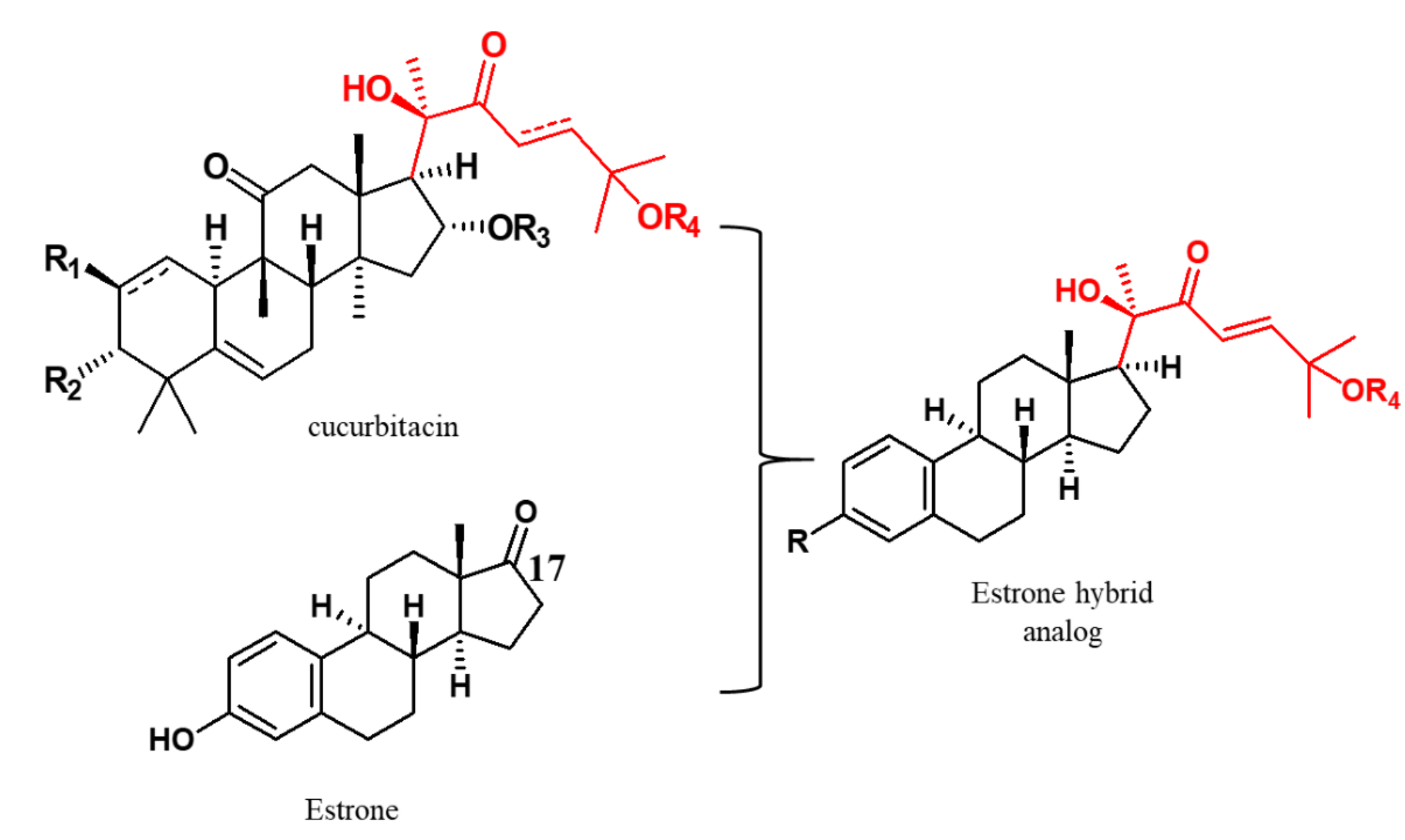

Figure 3. Scheme for synthesizing compounds.

Table 1. Cytotoxicity of promising estrone analogs

\begin{tabular}{|c|c|}
\hline Compound & MDA-MB-468 \\
\hline MMA300 & $0.89 \pm 0.10$ \\
\hline MMA307 & $0.85 \pm 0.00$ \\
\hline MMA320 & $1.71 \pm 0.01$ \\
\hline MMA321 & $0.56 \pm 0.01$ \\
\hline Sorafenib & $10.09 \pm 0.68$ \\
\hline
\end{tabular}

$\mathrm{IC}_{50}$ values were calculated by non-linear regression analysis. Values represent Mean \pm SD of quadruplicate experiment $(n=4)$.
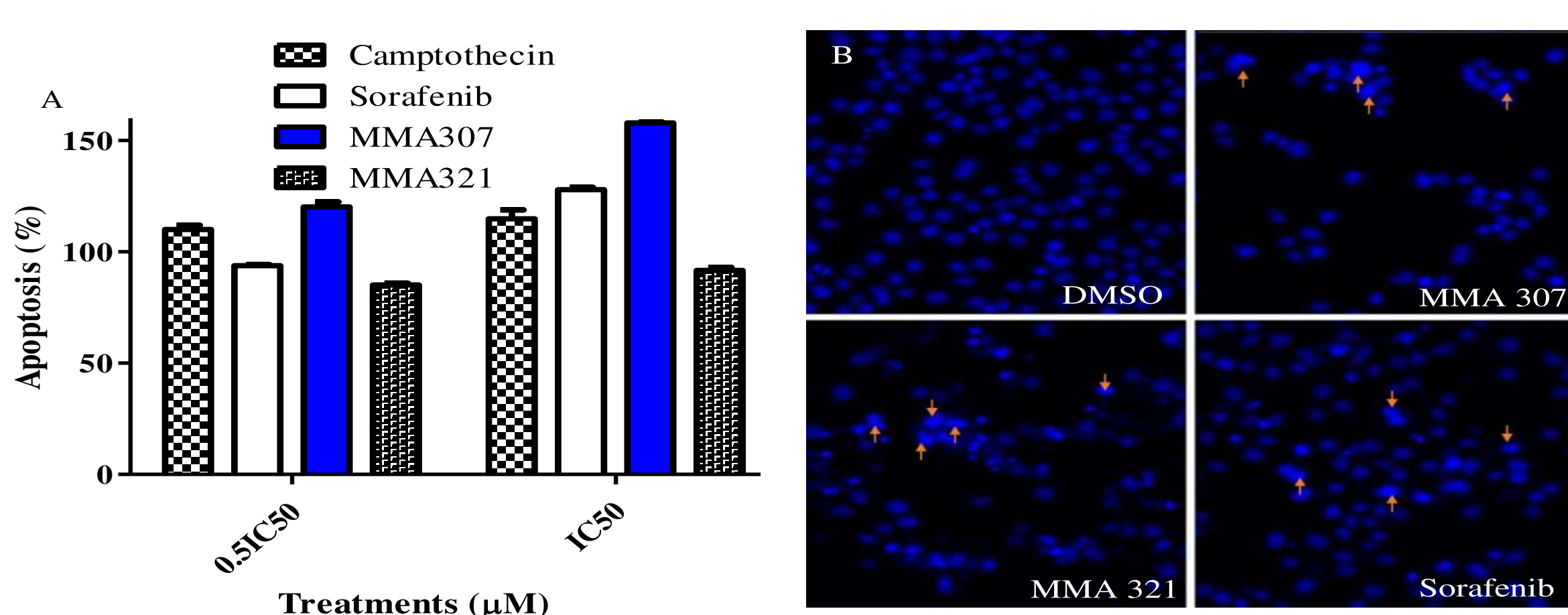

Figure 4. Initial apoptosis induction and chromatin condensation observed in MDA-MB-468 cells assayed by Annexin V (A) and Hoechst staining (B). Luminescence was measured by a plate reader and images were acquired using Cytation 3 imaging multi-mode reader.
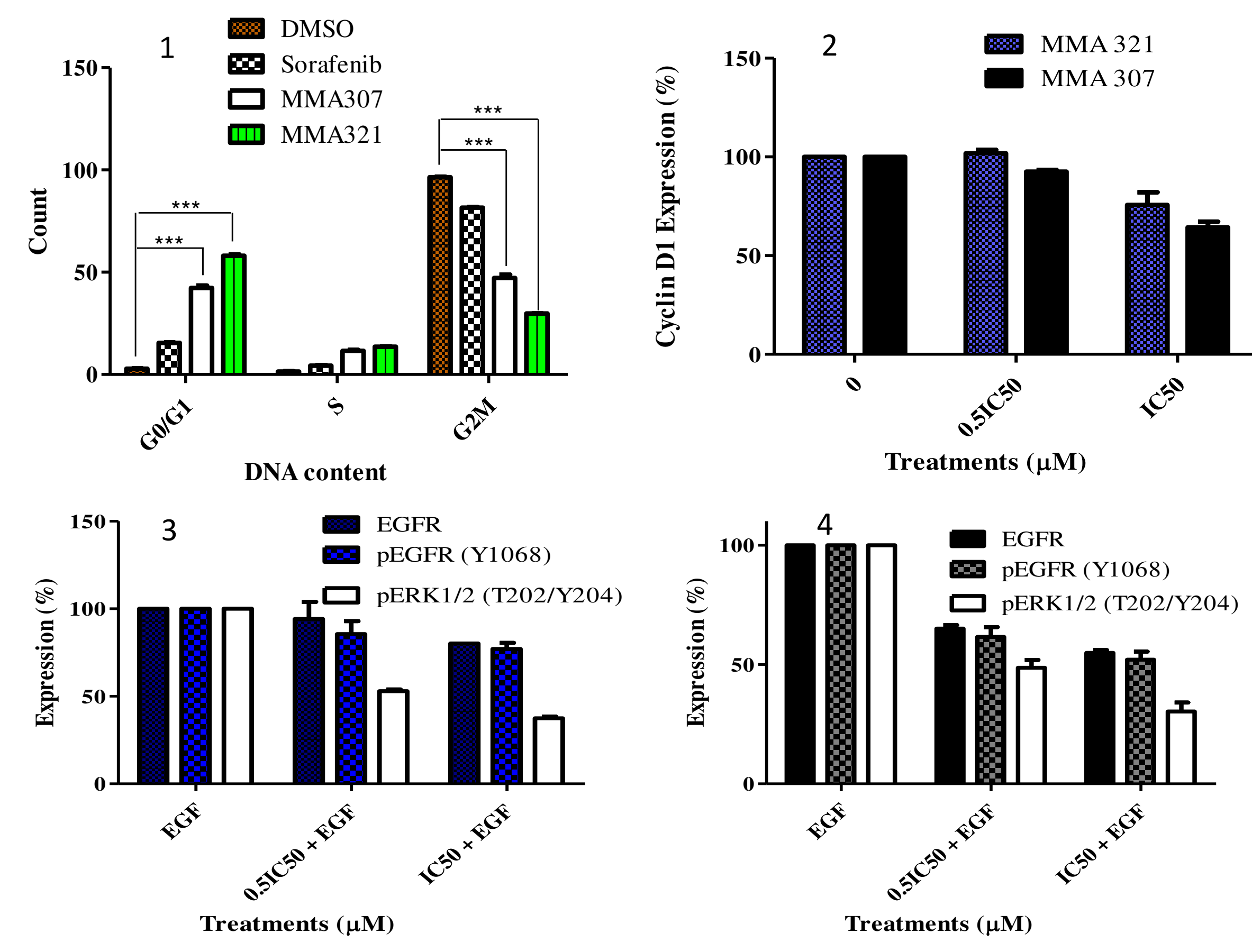

Figure 5. MDA-MB-468 cells exposure to estrone analogs resulted in cell cycle arrest (1), cyclin D1 downregulation (2), and suppression of EGFR and its downstream protein levels $(3-4)$. ${ }^{* * *} \mathrm{P}<0.001$

\section{Conclusion}

Estrone analogs were potent against EGFR kinase domain in silico.

The compounds induced apoptosis and suppressed EGFR signaling to halt the growth of TNBC cells.

Reference: 'Bray et al, 2018. Global cancer statistics 2018: GLOBOCAN estimates of incidence and mortality worldwide for 36 cancers in 185 countries. CA: a Cancer Journal for
Clinicians, 68(6), 394-424. 